\title{
DO LASER SCAN À EXPERIÊNCIA EM REALIDADE VIRTUAL IMERSIVA EM MODELOS BIM: EXPERIÊNCIAS E TESTEMUNHOS
}

\author{
Joana Gomes ${ }^{(1)}$, Sara Eloy ${ }^{(1)}$ \\ (1) Instituto Universitário de Lisboa (ISCTE-IUL) ISTAR-IUL, Lisboa
}

\begin{abstract}
Resumo
Intervir em edifícios existentes e outros espaços construídos requer, tal como acontece no projeto de edifícios novos, o total controlo sobre o espaço no qual se vai intervir. Um projeto baseado em premissas incorretas é um fator primordial para o insucesso de uma intervenção. $\mathrm{O}$ controlo que é necessário ter num projeto de reabilitação arquitetónica obriga a que o levantamento do edifício seja bastante preciso.

O estudo aqui apresentado iniciou-se pela constatação desta necessidade e do facto de o 3D laser scan constituir uma ferramenta excecional para realizar o levantamento do edificado. Através desta tecnologia é possível digitalizar o território e recolher dados que, depois de tratados, permitem construir um modelo tridimensional que reproduz digitalmente o edifício real.

Este estudo pretende assim explorar as potencialidades trazidas pelo uso combinado das mais recentes tecnologias de levantamento, modelação e visualização de edifícios existentes a ser alvo de reabilitação. São essas tecnologias: o 3D Laser Scanning, a metodologia BIM e a Realidade Virtual imersiva.

O trabalho, realizado em meio académico, procura mostrar a utilização deste sistema no desenvolvimento do projeto de arquitetura. Neste sentido foram acompanhados dois casos reais e realizado um caso prático. Como caso prático foi realizado um levantamento recorrendo à ferramenta de 3D Laser Scanning num edifício existente a ser alvo de projeto de reabilitação e realizada a modelação assente na metodologia BIM sobre esse levantamento. Durante o trabalho foi ainda realizada a visualização num ambiente de navegação imersivo por meio de Realidade Virtual, quer num primeiro momento de visualização da nuvem de pontos obtida pelo 3D Laser Scanning quer num segundo momento na visualização do modelo BIM.
\end{abstract}

\section{Introdução}

O processo de compreensão de uma obra de arquitetura, tanto em novas construções como em edifícios existentes exige um controlo total do espaço. [1] Uma documentação espacial com pouco rigor e pouco objetiva conduz, na maioria das vezes, ao insucesso do projeto de 
arquitetura. Uma base de projeto, somente apoiada em desenhos bidimensionais com um rigor aproximado e representando apenas parte da realidade, é uma das principais lacunas durante o processo de projeto. [2]

Nos últimos anos, surgiram ferramentas como o 3D Laser Scanning, que visam aprofundar o conhecimento espacial, cruzando e recolhendo uma grande quantidade de dados que depois de tratados em software especializados permitem obter modelos digitais tridimensionais que simulam com grande rigor o objeto real. [3] Hoje, após uma reflexão dos vários aspetos que têm progressivamente tornado os métodos tradicionais de levantamento de edifícios obsoletos coloca-se uma questão fundamental: como pode a tecnologia 3D Laser Scanning colmatar a fraca documentação ao longo do processo de obra?

Neste contexto propôs-se os seguintes objetivos para este trabalho (os pontos enunciados em seguida encontram-se desenvolvidos em [4]): i) Identificar e estudar o hardware de 3D Laser Scanning disponível; ii) Apresentar as vantagens e desvantagens do método na fase de levantamento; iii) Aplicar o processo de levantamento por 3D Laser Scanning em projeto e analisar os resultados obtidos; iv) Fazer um breve retrato do uso destas tecnologias por gabinetes de arquitetura portugueses; v) Identificar potenciais no uso de Realidade Virtual (RV) imersiva para visualização de nuvens de pontos.

\section{Estado da arte}

\subsection{Tecnologias de levantamento}

Tradicionalmente, o modo de recolha e representação dos dados geométricos de um edifício baseia-se num processo de recolha e posterior registo de elementos realizado em duas fases bastante distintas e que, pela natureza das ferramentas que são usadas, conduz frequentemente a um entendimento pobre do objeto construído. [5]

A evolução tecnológica destes últimos anos fez surgir novos métodos de levantamento, métodos esses que permitem que a recolha de informação do espaço construído se traduza instantaneamente em informação tridimensional. Nesta aproximação pode-se encontrar algumas tecnologias como o 3D 3D Laser Scanning.

Nos últimos anos a tecnologia 3D Laser Scanning desenvolveu-se de uma forma impressionante. Quase todos os sistemas laser utilizados dão uso ao GPS como meio de orientação. Trata-se de um método recente com um número limitado de fornecedores, e ainda bastante dispendioso. [6]

Um sistema de 3D Laser Scanning recolhe informação tridimensional de um objeto e usa uma nuvem de pontos para registar tridimensionalmente a informação recolhida. Este processo faz scans (varrimentos) com diversos níveis de alcance, podendo recolher informação de um objeto a poucos metros da estação de recolha ou mesmo a quilómetros de distância, dependendo do alcance do equipamento. A nuvem de pontos obtida guarda todos os componentes espaciais identificados. Uma nuvem de pontos refere-se a uma base de dados onde são armazenados pontos com coordenadas tridimensionais. Normalmente, se os registos do scan sobrepuserem entre si alguma da informação recolhida, o software realiza o registo automaticamente, otimizando o processo de criação de uma nuvem de pontos tridimensional. [7] 


\subsection{BIM}

Associado à tecnologia BIM, o 3D Laser Scanning permite auxiliar na redução de conflitos entre especialidades, no caso de obras novas e reabilitações. A tecnologia BIM permite usar a nuvem de pontos e traduzi-la, mais um menos automaticamente, num modelo tridimensional da informação recolhida. A tecnologia de modelação tridimensional baseada em BIM associa à tradicional modelação geométrica do CAD a criação de modelos inteligentes de edifícios que contém informação sobre a sua materialidade e processos de construção. Os modelos realizados em BIM permitem acompanhar o ciclo de vida de um edifício e utilizá-lo durante intervenções futuras que possam acontecer com vantagens nos processos de construção, simulação, orçamentação e outros. Esta tecnologia fomenta a colaboração multidisciplinar entre as especialidades envolvidas no projeto de edifícios e sobretudo a fluidez, em tempo real, da disponibilização da informação.

\subsection{Realidade Virtual Imersiva}

Diversos tipos de soluções tecnológicas encontram-se disponíveis para a experiência de realidades alternativas com diversos níveis de imersão e sensação de presença sendo que destes é importante destacar a Realidade Virtual (RV), a Realidade Aumentada (RA) e a multimédia $360^{\circ}$ como vídeos ou fotografias. [8]

A RV trouxe oportunidades novas que expandiram as potencialidades de experienciar mundos virtuais e esta foi fortemente aceite quer por técnicos quer pelo público geral. [9] Um ambiente de RV trata-se de uma simulação totalmente virtual que representa um mundo, real ou imaginário, no qual o interveniente se encontra imerso. Os dispositivos mais comumente utilizados nesta tecnologia para experienciar esses mundos virtuais incluem os Head Mounted Displays (HMD), as CAVE e as Powerwall. [10]

\section{Casos de estudo}

No âmbito deste trabalho foram desenvolvidos e analisados três casos de estudo, dois em meio profissional, na empresa FVPS onde a primeira autora trabalhou, e um em meio académico:

\section{Caso 1}

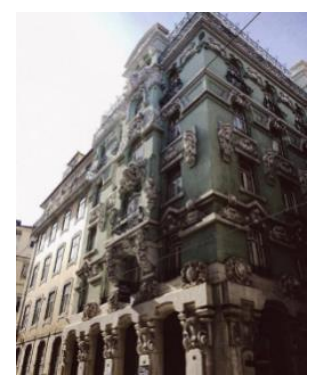

Localização:Lisboa, Portugal

Data de construção: séc.XX Localização:Sintra, Portugal

Tipologia: Habitação coletiva Data de construção: séc. XX a ser transformada em Alojamento temporário
Caso 2

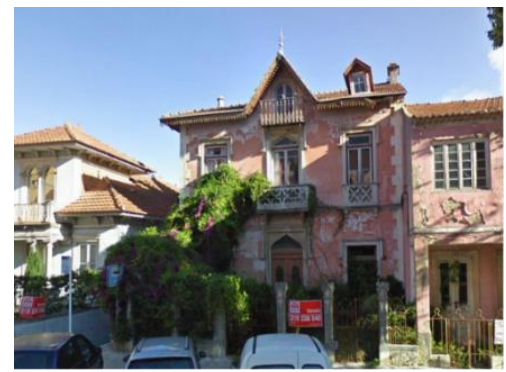

Tipologia: Habitação
Caso 3

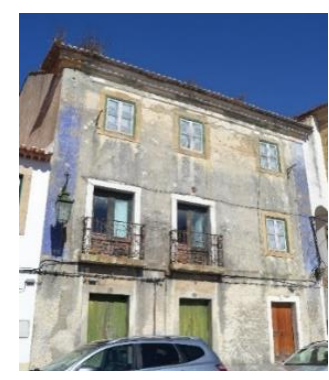

Localização:Alenquer, Portugal

Data de construção:séc. XIX Tipologia:Habitação e comércio 


\subsection{Caso 1}

O primeiro caso de estudo consistiu no levantamento e modelação de um edifício do início do século XX em Lisboa. Este levantamento foi realizado usando uma estação P30 da Leica tendo sido realizado um total de 350 scans, entre interiores e exteriores do edifício. O trabalho tinha como objetivo a realização do modelo BIM que serviria de base para o projeto de reabilitação a que o edifício seria alvo (Figura 1).

Dada a complexidade do edifício, principalmente da sua fachada, a nuvem foi divida por zona interior e exterior e, de forma a conservar o grau de detalhe requerido pelo arquiteto relativamente aos elementos escultórios da fachada, foi necessário realizar um passo intermédio antes da passagem da nuvem para BIM. Nesse passo, os elementos foram transformados em malhas poligonais (meshes) (Figura 2). Apesar de visualmente esta alteração ter sido eficaz, não foi a mais indicada na conceção do modelo quer por questões de tempo despendido no processo quer por incompatibilidades que se viriam a verificar quando o ficheiro foi convertido em ficheiro ifc (Industry Foundation Class file). Concluiu-se neste estudo que, apesar de se desejar representar de forma bastante realista os elementos escultóricos de um edifício, à semelhança do que acontece nos levantamentos tradicionais, deve ser realizada uma simplificação dos dados que são obtidos e ter em consideração a escala de pormenor a que se pretende chegar.

$\mathrm{O}$ atelier requerente mostrou-se bastante satisfeito com o resultado do modelo obtido.
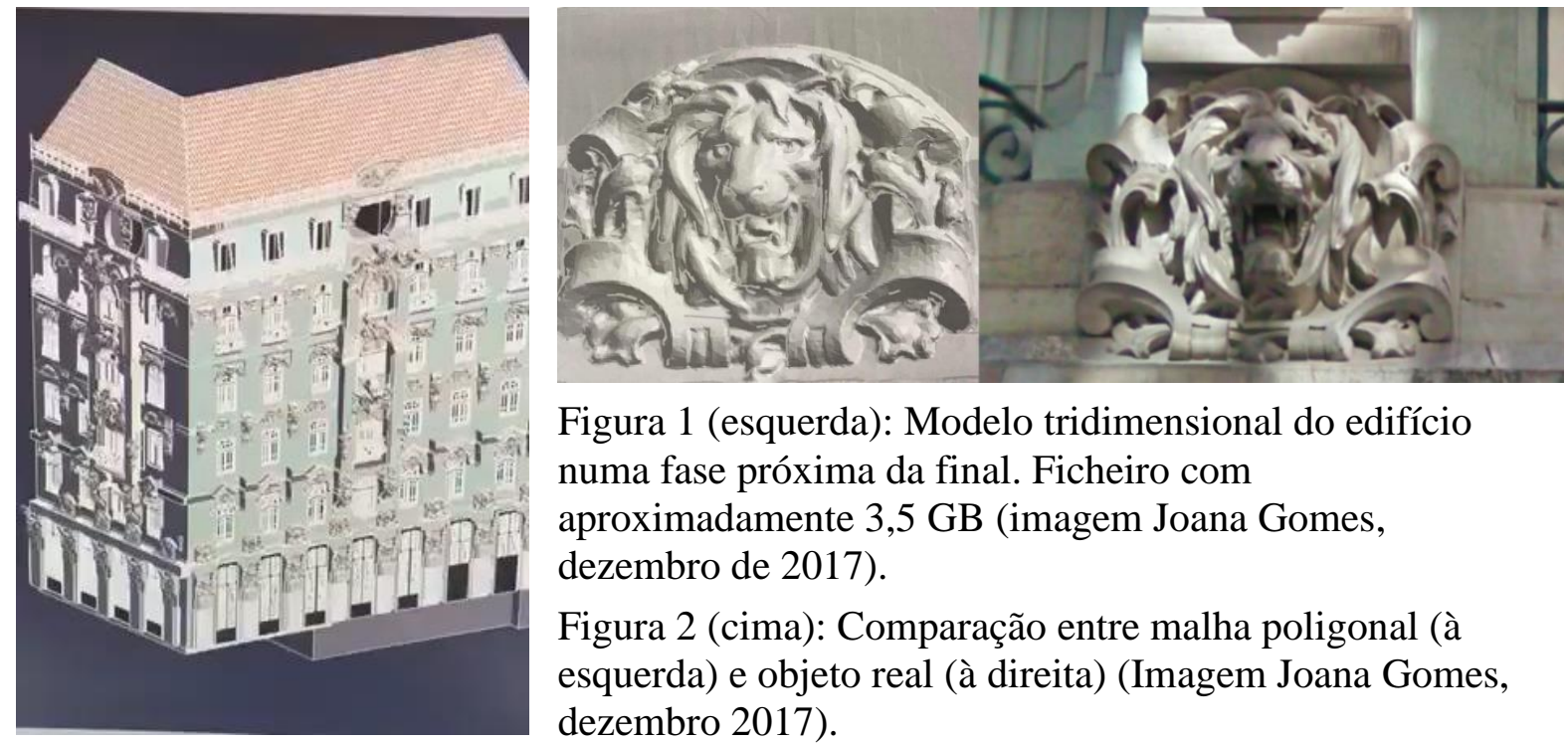

Figura 1 (esquerda): Modelo tridimensional do edifício numa fase próxima da final. Ficheiro com aproximadamente 3,5 GB (imagem Joana Gomes, dezembro de 2017).

Figura 2 (cima): Comparação entre malha poligonal (à esquerda) e objeto real (à direita) (Imagem Joana Gomes, dezembro 2017).

\subsection{Caso 2}

O segundo caso de estudo, o levantamento e modelação de um edifício localizado em Sintra, foi um dos primeiros realizado pela empresa FVPS. Para o atelier este projeto serviu de mote para se iniciarem no uso do processo Scan to BIM. O cliente necessitava de um modelo BIM que serviria de base para as várias especialidades.

O processo de scan do edifício prolongou-se por sete horas incluindo registos interiores de todos os pisos e do ambiente exterior envolvente. Em todo o processo foram realizados cerca de 40 disparos da estação de recolha Leica P30, normalmente realizando-se dois disparos por divisão regular. Como alguns dos espaços interiores possuíam espelhos, estes tiveram de ser retirados já que este tipo de objeto entra em conflito com os scans, distorcendo e causando erros de 
precisão. Visto que o 3D Laser Scanning não permite obter informação sobre os elementos construtivos dos edifícios digitalizados, essa informação teve de ser recolhida paralelamente. Assim, o registo da constituição construtiva do edifício foi realizado através da observação dos elementos (que devido a patologias diversas tinham a descoberto o seu interior) e ainda por meio de amostras onde foi retirada a camada visível do elemento.

Os dados recolhidos pela estação de 3D Laser Scanning foram posteriormente inseridos no Recap Pro, transformados em ficheiro .ptx (formato tipo ASCII para salvar dados de nuvens de pontos) e unificados. Neste software foi realizada uma breve análise que visou a identificação rápida de deformações ou outras anomalias para posteriormente a nuvem ser exportada para 0 software de BIM Autodesk Revit ${ }^{2}$ com o objetivo de desenvolver o modelo 3D.

De forma a facilitar o desenho detalhado dos pormenores na fachada, foi isolado o elemento em questão no software de transformação e visualização da nuvem de pontos (Autodesk RecapPro $^{3}$ ) e inserido numa região que continha apenas o pormenor a modelar (Figura 3).

Um facto notório a reter neste momento do processo foi a quantidade de informação disponível na nuvem gerada que acabou por se revelar um problema recorrente desta técnica de levantamento.

Enquanto que num processo tradicional de levantamento o foco é a extração apenas do necessário, com a introdução do 3D Laser Scanning, este foco deixa de ser aparentemente necessário e cai-se frequentemente no erro de extrair informação em quantidade excessiva que depois é difícil de gerir por alguma incapacidade da tecnologia (necessidades de computadores muito potentes) e tempo de trabalho. Acontece também que, este método cria uma quantidade demasiado grande de informação a processar em simultâneo e acontece que alguns elementos acabam por passar despercebidos como pequenos vãos perto de mobiliário ou diferentes níveis em espaços com geometrias mais complexas. Devem assim ser definidos a priori os graus de detalhe pretendidos de modo a evitar a representação de detalhe em excesso, tornando o levantamento contraprodutivo se esse detalhe a modelar não for utilizado, ou em falta, o que pode dar origem à necessidade de novo levantamento

Face ao levantamento obtido, o atelier de arquitetura parceiro que ficou encarregue da especialidade de arquitetura mostrou-se muito satisfeito com o facto ter todo o edifício e todas as suas infraestruturas modeladas em BIM e por isso estas ficarem registadas para uma posterior manutenção do edifício.

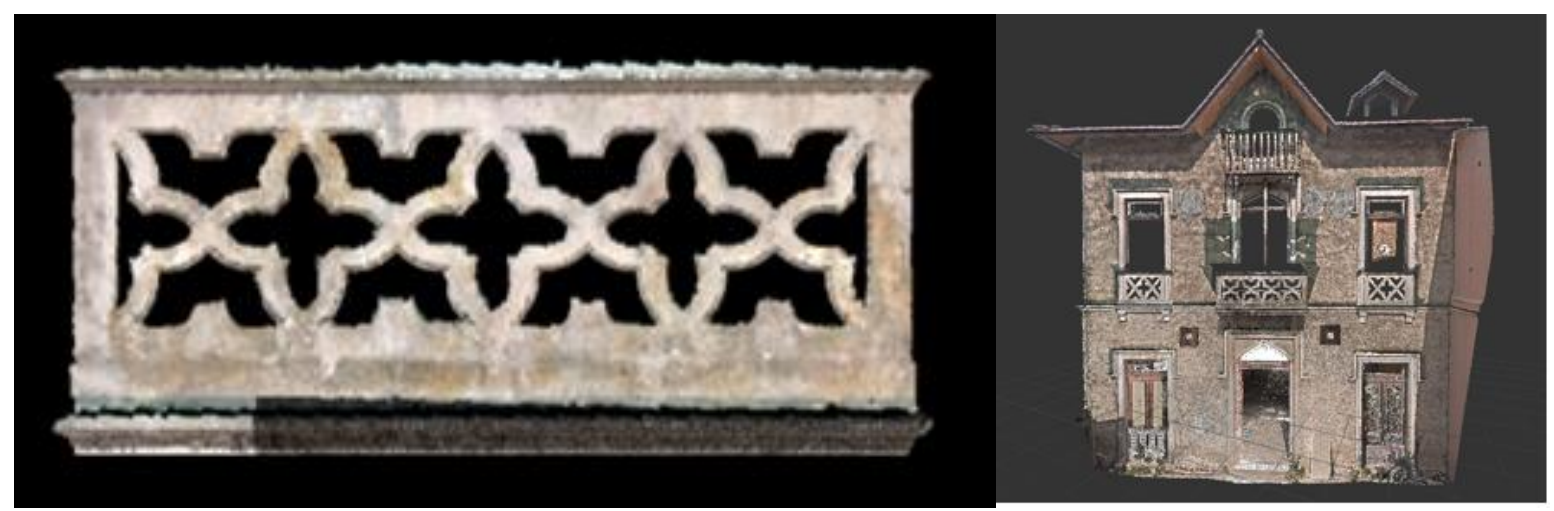

Figura 3: Fachada do Edifício e pormenor no Recap Pro (Crédito Fotográfico FVPS, 2013).

\footnotetext{
${ }^{2}$ https://www.autodesk.pt/products/revit/overview

${ }^{3}$ https://www.autodesk.com/products/recap/overview
} 


\subsection{Caso 3}

Este caso foi realizado em âmbito académico no decorrer do último ano do Mestrado Integrado em Arquitetura e visava intervir num edifício do século XIX na Vila de Alenquer, Portugal. O trabalho dividiu-se em quatro fases: i) captura da nuvem de pontos; ii) preparação da nuvem de pontos com software específico (Leica Cyclone ${ }^{4}$ e Autodesk Recap Pro); iii) Modelação BIM do edifício original no Autodesk Revit; iv) visualização da nuvem de pontos em RV imersiva através do uso do software $\operatorname{Unity}^{5}$ (para visualização da nuvem de pontos) e do plugin Enscape ${ }^{6}$ (para visualização do modelo BIM)).

\section{Fase 1 - Captura da nuvem de pontos}

O levantamento interior e exterior do edifício realizou-se recorrendo a uma ScanStation Leica P30. O levantamento prolongou-se por quatro horas na totalidade num total de 34 disparos da estação de recolha. Em todos os compartimentos foram realizados scans na entrada e perto do centro do compartimento. De cada vez que a estação era colocada num local específico do edifício, esta tinha de ser recalibrada. Não quantificando o tempo de preparação do equipamento, que variava bastante, a recolha em cada disparo demorava cerca de dois minutos - aproximadamente o tempo que demora a recolher a vista $360^{\circ}$ detalhada do disparo e a processá-la. Para evitar ocultação de informação espacial a recolha foi realizada sem a permanência de pessoas no local. É ainda de referir que, para melhorar o alcance do laser, as portas existentes nos compartimentos foram retiradas.

\section{Fase 2 - Preparação da nuvem de pontos}

Depois de recolhidas as informações necessárias pela estação de 3D Laser Scanning, os dados em formato binário foram transferidos para uma workstation para posteriormente serem transformados em .ptx. Isto acontece dado que o software Recap não aceita ficheiros binários tal como são obtidos da estação de recolha.

Primeiramente os ficheiros binários foram importados para o Cyclone onde se efetuou a sua conversão para formato .ptx e posteriormente importaram-se estes .ptx através do Recap para que, com este software, esses dados fossem unificados e se gerasse o modelo de nuvem de pontos (Figura 4). É recorrente que nesta fase o software não seja capaz de detetar todas as partes comuns entre os scans, sendo que depois de realizado o registo automático sugerido pelo software, o mesmo mostra as incongruências entre os registos e sugere que estes sejam unidos pelo utilizador. Neste passo é usual encontrar imprecisões pelo que é dada a oportunidade ao utilizador de fazer a sua própria combinação (Figura 5).

\footnotetext{
${ }^{4}$ https://leica-geosystems.com/products/laser-scanners/software/leica-cyclone

${ }^{5}$ https://unity.com/

${ }^{6}$ https://enscape3d.com/
} 


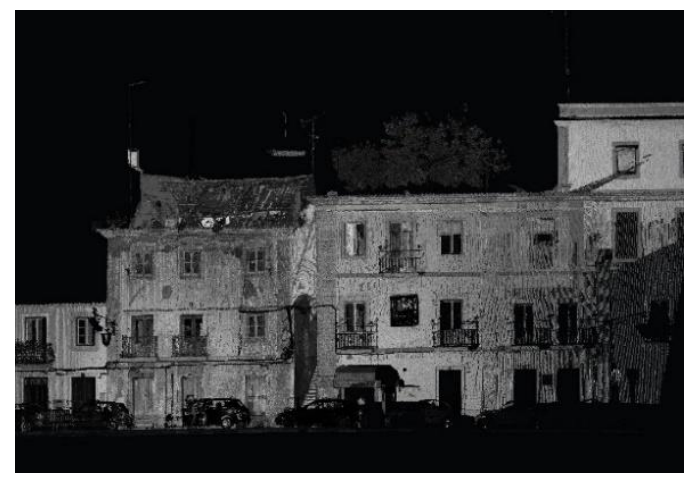

Figura 4: Visualização da Nuvem de Pontos no Recap Pro.

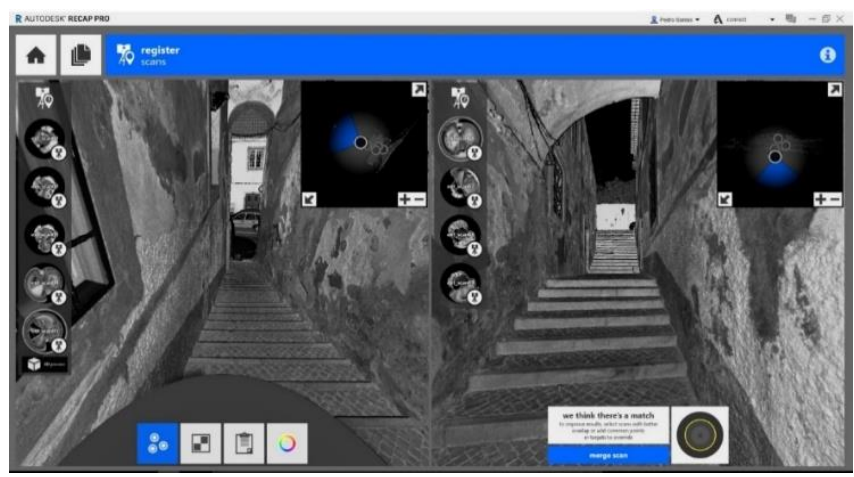

Figura 5: Registo manual - possível combinação de scans.

\section{Fase 3 - Modelação em BIM do original}

Com a exportação da nuvem para o Revit foi então possível dar início à modelação.

Depois de inserida a nuvem no Revit é definido o norte do projeto de forma a georreferenciálo. Quando todos os dados iniciais relativos ao espaço em que se insere o edifício são aplicados, definem-se então os Levels, ou seja, a altimetria referente a cada piso/nível. Em seguida, depois de criados todos os níveis e grelhas auxiliares para a construção do modelo começam-se então a criar as famílias de objetos. Nos elementos em que se verificou que as dimensões não tinham grande variação não foi realizada a sua parametrização (Figura 6).

Relativamente à modelação de paredes, pavimentos e escadas, nem sempre foi possível conseguir a geometria adequada recorrendo ao comando da categoria a que pertencem. De facto, por se tratarem de elementos antigos irregulares, deformados e com espessura bastante variável (Figura 7) recorreu-se em diversos momentos a modelação alternativa. É de salientar também que, num processo tradicional de levantamento, muitas destas caraterísticas dos elementos não seriam considerados, o que nos conduz, novamente à questão do volume de informação disponibilizada pela nuvem e ao grau de precisão com que queremos modelar. Isto não se traduz necessariamente numa modelação incorreta visto que os elementos em questão seriam em grande parte para demolir; nestes casos, para efeitos de medições interessava saber características como o metro linear, a altura e espessura das mesmas e não a sua categorização. Como no projeto se previa a demolição das estruturas interiores de madeira, também tendo em consideração o seu estado, optou-se simplesmente por representar as paredes interiores e os pavimentos sem detalhe estrutural, representando apenas as suas irregularidades ou deformações de forma genérica. Todos os outros elementos do modelo foram modelados à semelhança da informação recolhida com a nuvem de pontos. 


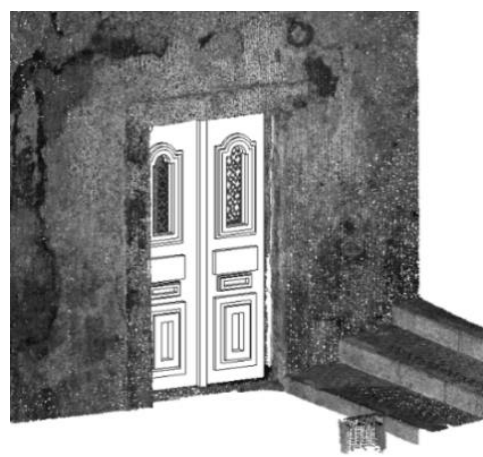

Figura 6: Nuvem de pontos com uma família de porta criada e baseada na geometria semelhante à do projeto mas sem parametrização. Sobreposição com a nuvem de pontos no Revit.

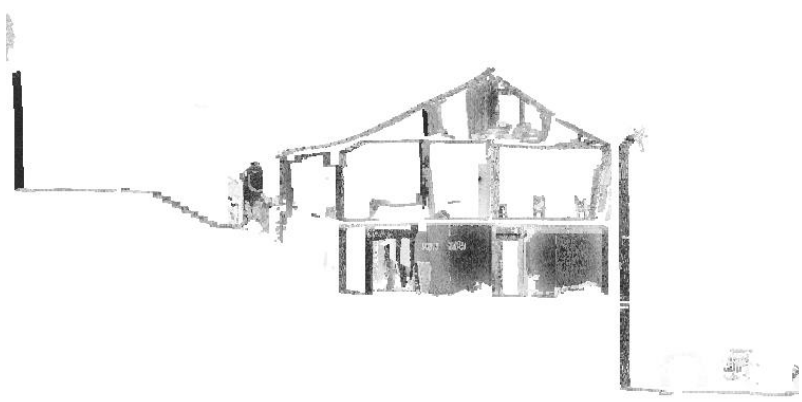

Figura 7: perfil de corte longitudinal efetuado sobre o modelo de nuvem de pontos.

\section{Fase 4 - Nuvem de pontos e modelo BIM em realidade virtual imersiva}

A RV imersiva é aqui apresentada como uma forma de visualização mais realista e que dá maior informação do edificado existente e do novo espaço proposto.

A visualização da nuvem de pontos através de RV imersiva foi feita através do uso de um HMD - Oculus Rift - e o software Unity. Para importar a nuvem de pontos para o Unity esta foi primeiramente corrigida através da importação do ficheiro proveniente do Recap para o CloudCompare $^{7}$ (software utilizado para analisar e resolver problemas da nuvem de pontos). Neste caso a escala foi aumentada e o número de pontos reduzido. Seguidamente foi utilizado um script no Unity que permitia a leitura das coordenadas dos pontos e que procedia à sua substituição por esferas que se comportam como pontos (Figura 8). Constatou-se imediatamente que o número de pontos da nuvem era demasiado grande para o software Unity processar e permitir a fluidez de navegação em RV que se pretendia. Por esta razão foram feitas várias tentativas de redução do número de pontos até se encontrar uma solução que permitia não só a visualização do espaço em questão como também a navegação no modelo com uma boa taxa de fotograma.

Para a visualização do modelo BIM em RV foi utilizado um plugin de visualização para o Revit - Enscape - que permite visualizar em RV o modelo 3D sem a execução de passos intermédios (Figura 9). A visualização em RV imersiva traz a possibilidade de os utilizadores visualizarem à escala real o modelo do edifício, navegarem por ele e observarem-no em todos os ângulos e com isso detetarem possíveis conflitos assim como validarem opções de projeto sobre as quais existiam dúvidas. De notar que este plugin não suporta a visualização de nuvem de pontos.

\footnotetext{
${ }^{7}$ https://www.danielgm.net/cc/
} 


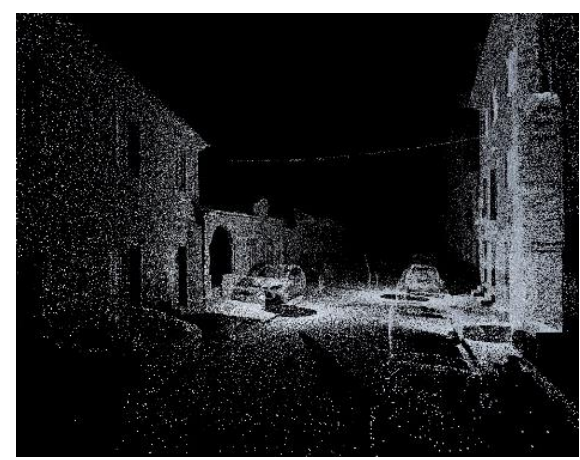

Figura 8: Visualização da nuvem de pontos no Unity.

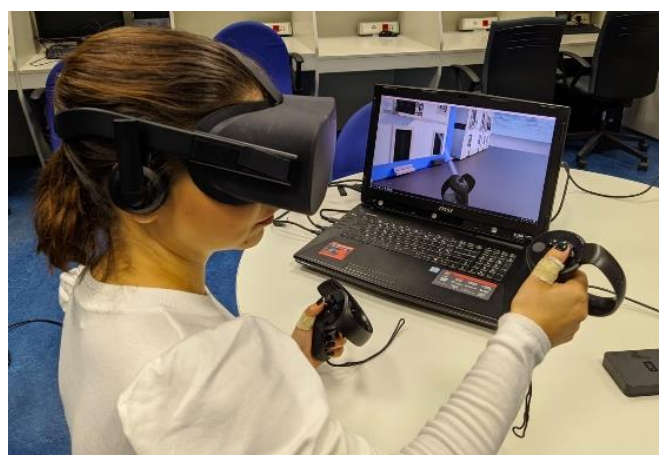

Figura 9: Visualização da nuvem de pontos no Enscape através dos Oculus Rift. (imagem Joana Gomes, fevereiro de 2020).

\section{Discussão}

Considerando a questão inicial desta investigação, pode-se concluir que com a nuvem de pontos foi de facto possível conseguir um nível de precisão muito grande, ao contrário do que acontece com os métodos tradicionais de levantamento.

No caso específico deste edifício percebeu-se rapidamente o estado de degradação do mesmo. Através da nuvem de pontos foi ainda possível certificarmo-nos do bom estado das fachadas do edifício e confirmar que o problema que instigou a deterioração do edifício foi a sua cobertura. De facto, a antiguidade da construção, as diversas intempéries por que passou, e a pouca manutenção que recebeu, foram fatores que contribuíram para o seu estado de deterioração. .

A utilização do 3D Laser Scanning associado ao BIM possibilitou representar fielmente a realidade existente assim como manter a informação de todo o edifício sistematizada e organizada num único local, acessível a qualquer interveniente no projeto. Com este método e associando a RV imersiva para a visualização do edifício à escala real, foi possível estudar diferentes soluções com bastante eficiência para problemas que foram surgindo no decorrer do projeto.

Também o facto de experienciar a nuvem de pontos em RV imersiva permitiu obter uma imagem muito mais clara da realidade relativamente à visualização dessa mesma nuvem sem a imersividade. A sensação de presença que a RV nos traz ajuda a ter presente a memória do edifício durante o processo de conceção do projeto que neste caso se traduziu com a utilização da nuvem de pontos.

\section{Aplicação em ateliers de arquitetura}

Nesta secção descreve-se sucintamente um retrato do uso destas tecnologias nos gabinetes de arquitetura em Portugal através de uma análise feita entre maio e setembro de 2018.

De forma a fundamentar as conclusões relativas ao método, foram realizadas entrevistas a seis arquitetos cuja atividade inclui em grande medida reabilitar edifícios existentes. O objetivo foi recolher informação sobre o conhecimento que estes ateliers têm sobre a tecnologia laser, fazendo um breve retrato, no panorama português, da utilização desta técnica de levantamento. 
Os arquitetos entrevistados foram: arquiteto Luís Mateus; Atelier Aponto, arquitetos Marina Félix e Gian Paolo Cilurzo; Montenegro Arquitetos, arquiteto Nuno Montenegro; Atelier Marta Campos, arquiteta Marta Campos; Atelier Appleton \& Domingos, arquiteto João Appleton; arquiteto Sebastien Roux.

A aceitação e aderência a levantamentos por meio de 3D Laser Scanning associados à metodologia BIM está relacionado com a predisposição dos ateliers em adotar novas técnicas e em se atualizarem. Ateliers mais focados no mercado português como é o caso do Atelier Aponto, têm dificuldade em ver os benefícios das novas tecnologias, apontando o elevado valor que teriam de despender como uma das razões fulcrais que inibe essa mudança.

Normalmente, os ateliers que adotam o 3D Laser Scanning, como o de Marta Campos, já reconhecem o benefício deste em utilização simultânea com BIM e por isso assumem que se trata apenas de otimizar tempo e trabalho. Para João Appleton, o BIM ainda parece uma realidade muito distante e não vê benefício algum em oferecer aos seus colaboradores formação em software específico nesta tecnologia. Apesar disso reconhece a eficácia do 3D Laser Scanning mas prefere aplicá-lo no desenho 2D.

No geral, os arquitetos têm conhecimento tanto do 3D Laser Scanning como do BIM mas receiam avançar com estas tecnologias. É consensual que o gasto para integrar o 3D Laser Scanning nas empresas é, por enquanto, muito elevado e os ateliers de projeto não estão dispostos a realizar esse investimento.

\section{Considerações Finais}

Através das nuvens de pontos geradas pelo 3D Laser Scanning a informação gerada torna-se muito mais rigorosa e consistente do que através de um sistema tradicional de levantamento. A sua utilização fornece bases exatas que, juntamente com outras informações recolhidas como fotografias e pequenos esquiços do local, permitem o planeamento adequado da intervenção. Contudo, a utilização de 3D Laser Scanning levanta algumas questões quando aplicada a edifícios existentes. Por muito boa que seja a qualidade da informação extraída das nuvens de pontos, esta apenas permite uma análise geométrica e de deformações estruturais, não podendo fornecer informações sobre elementos invisíveis por exemplo de camadas internas das paredes sem que sejam realizadas demolições das mesmas. Toda a informação sobre o que está sob a superfície do elemento de construção precisa ser obtida com outras técnicas.

No caso da associação da nuvem de pontos ao BIM surge a questão de como realizar uma modelação eficaz. Será o esforço de modelação realmente necessário? Para lidar com esse problema torna-se essencial analisar a geometria dos elementos que constituem o edifício. Esta análise pode ser realizada com facilidade através da visualização da nuvem de pontos num ambiente de RV imersiva. No entanto, a introdução desta tecnologia, segundo a metodologia de exportação da nuvem de pontos utilizada neste estudo implica também ela conhecimento extra noutros software. Contudo, algumas das empresas de software começam já a tornar o processo de visualização em RV muito mais intuitiva e integrado pelo que se vai tornando uma ferramenta mais comum e de fácil acesso.

Um atelier encarregue de realizar a conversão dos dados das nuvens em modelo deverá estar devidamente habilitado com competências adequadas para poder compreender e decidir sobre o que deverá ser realizado e como tornar o diálogo entre a equipa projetista e a encarregue do levantamento mais eficiente. 
Anteriormente à modelação deve ser acordado entre os vários intervenientes no projeto, qual o objetivo do projeto, as tolerâncias a considerar e qual o tipo de conteúdo a apresentar no modelo. A comunicação entre as partes interessadas deve ser bastante clara.

Através dos depoimentos recolhidos durante as entrevistas, constata-se que existe ainda um grande caminho a percorrer para que a utilização da nuvem de pontos e do BIM em simultâneo seja uma realidade. Apesar do esforço de alguns ateliers em integrar estas novas realidades, as ferramentas são consideradas ainda muito iniciais e receiam-se os erros e dificuldades de adaptação, nomeadamente a utilização dos IFC, e os critérios de modelação, entre outros.

\section{Agradecimentos}

Esta publicação foi parcialmente financiada pelo projeto FCT UIDB/04466/2020.

\section{Referências}

[1] D. Di Mascio and P. Palka, "From the 3D survey 'ad Oggetto' to the technological representation of the architecture," in Respecting Fragile Places: 29th eCAADe Conference Proceedings, 2011, pp. 829-836.

[2] L. M. C. Mateus, "Contributos Para o Projecto de Conservação, Restauro e Reabilitação. Uma Metodologia Documental Baseada na Fotogrametria Digital e no Varrimento Laser 3D Terrestres (v.2)," Universidade Técnica de Lisboa, 2012.

[3] C. Tonn and O. Bringmann, "Point clouds to BIM Methods for building parts fitting in laser scan data," in The next city - New technologies and the future of the built environment (16th International Conference CAAD Futures 2015), 2015, pp. 358-369.

[4] J. Gomes, "Do laser Scan à modelação BIM: experiências e testemunhos," ISCTE-Instituto Universitário de Lisboa, 2018.

[5] E. B. Anil, P. Tang, B. Akinci, and D. Huber, "Assessment of Quality of As-is Building Information Models Generated from Point Clouds Using Deviation Analysis," in Proceedings of SPIE - The International Society for Optical Engineering, 2011.

[6] E. P. Baltsavias, "A comparison between photogrammetry and 3D Laser Scanning," ISPRS J. Photogramm. Remote Sens., vol. 54, no. 2-3, pp. 83-94, 1999.

[7] N.-J. Shih and P.-H. Wang, "Using point cloud to inspect the construction quality of wall finish," in Proceedings of the 22^nd eCAADe Conference, 2004, pp. 573-578.

[8] P. Milgram, H. Takemura, A. Utsumi, and F. Kishino, "Augmented Reality: A class of displays on the reality-virtuality continuum," Syst. Res., vol. 2351, no. Telemanipulator and Telepresence Technologies, pp. 282-292, 1994.

[9] P. Rosedale, "Virtual Reality: The Next Disruptor: A new kind of worldwide communication," IEEE Consum. Electron. Mag., vol. 6, no. 1, pp. 48-50, 2017.

[10] S. Eloy, L. Ourique, U. Wossner, J. Kieferle, W. Schotte, and M. S. Dias, "How present am I: three virtual reality facilities testing the fear of falling," in $e C A A D e 2018,2018$.

[11] J. Gomes, S. Eloy, N. P. Silva, R. Resende, and L. Dias, "A quasi-real virtual reality experience: point cloud navigation.," in Realities: Virtual as an aesthetic medium in architecture ideation., S. Eloy and N. Diniz, Eds. . 